УДК: 316.4

DOI: $10.17223 / 1998863 X / 33 / 11$

\title{
Т.Д. Подкладова
}

\section{МУЖЧИНА-ОТЕЦ В СЕМЬЕ И ОБЩЕСТВЕ: ВОВЛЕЧЕННОСТЬ VS. ИСКЛЮЧЕННОСТЬ}

\begin{abstract}
Современный мужчина-отец - это человек меняющийся. Происходящие трансформациии носят противоречивый, сложный, порой, конфликтный характер. Трансформация института семьи, гендерных ролей, формирование модели маскулинности приводят к появлению «вовлеченного отияа», для которого отцовство - это важнейшая часть его жизни и самореализации.

Ключевые слова: отиявство, маскулинность, мужчина, отец, семья, «включенное отияовство».
\end{abstract}

Исследования феномена отцовства, отцовских практик в современном обществе становятся востребованными в научном сообществе и привлекают внимание исследователей в рамках самых различных направлений: психологии, социологии, психиатрии, философии. Актуализация данного направления обусловлена несколькими факторами. В первую очередь, это связано с продолжающимися гендерными трансформациями, «перестройкой гендерного порядка» [1. С. 26] в современном обществе и, в частности, с изменением ролевой структуры мужчины.

Перемены в ролевом поведении мужчин и женщин, безусловно, связаны с меняющимися эталонами маскулинности и феминности, которые становятся менее однозначными и жесткими. Происходит очевидное ослабление традиционной гендерной поляризации. Фактически речь идет о формировании новой модели маскулинности как «внешне», так и «внутренне».

На этом фоне естественным образом происходит пересмотр ресурсов маскулинности: ролей, сценариев и инструментов ее реализации. Ресурсы, которыми пользуется большинство мужчин: статус, деньги, знаки престижа, семья, карьера, - сегодня недостаточны или не работают. «Мужественность» нового типа демонстрирует значимость иных ресурсов, таких как интеллектуальность, образованность, выдержанность. По мнению И. Костериной, важны не столько вышеуказанные качества сами по себе, сколько умение их использовать, демонстрировать и сочетать друг с другом [2].

Развивающийся в течение XX-XXI вв. конфликт между жесткими патриархальными нормами и перераспределением властных отношений в приватной сфере, как правило, иллюстрируется женскими трансформациями. Тем не менее мужчин это тоже касается. Кризис маскулинности обусловлен ослаблением традиционного мужского доминирования и связанного с этим изменения существующих представлений о мужественности, конфликт между трудовыми и семейными обязанностями. Все чаще отмечается противоречивость гендерных трансформаций. В частности, Кон писал о проявлениях данных противоречий у мужчин, когда покорность и покладистость в общественной жизни компенсируются жестокой тиранией дома и в семье по 
отношению к жене и детям, а «социальная пассивность и связанная с нею беспомощность компенсируются бегством от личной ответственности в беззаботный игровой мир вечного мальчишества. Не научившись в детстве самоконтролю и преодолению трудностей, такие мужчины навсегда отказываются от личной независимости, а вместе с ней от ответственности, передоверяя социальную ответственность начальству, а семейную - жене» [3. C. 101].

По мнению Ребекки Кей, современный российский мужчина попрежнему определяет себя, опираясь на советские представления о добытчике и трудяге, день и ночь зарабатывающем деньги, чтобы прокормить семью. Того, кто не может играть роль кормильца, клеймят как неудачника, слабака, неполноценного мужчину [4]. Это приводит к сильным эмоциональным переживаниям, нахождению в постоянной стрессовой ситуации, к депрессии.

Российские мужчины, в первую очередь молодые, постоянно испытывают давление со стороны сверстников, балансируя между ролью хорошего сына и крутого парня, довольно долго остаются экономически зависимыми от родителей, живут с ними. Безусловно, степень осознанности этих изменений и противоречий самим мужчиной во многом зависит от уровня его образованности, культуры, а также возможности выделить время для ролевой и Я-рефлексии в повседневной жизни.

Современный мужчина меняется. Сегодня мужчина более эмоционален, заботлив, нежен. Он признает необходимость гендерного равенства и ответственного отцовства. Повышение уровня образования и разнообразие культурного опыта делают его более терпимым. Но с другой стороны, мы можем наблюдать своеобразную дифференциацию, когда параллельно сосуществуют проявления маскулинности разных типов.

Одной из ведущих ролей мужчины является роль «отца». Варианты ее реализации разнообразны, и семья сегодня не является единственным пространством для этого. Современная семья, как известно, переживает серьезные изменения. Нужность самого института семьи и эффективность сосуществования людей в таком формате сегодня, как бы мы к этому ни относились, оценивается неоднозначно. Увеличивается число людей, не заключающих браки и выбирающих жизнь без детей. Так или иначе, общественные институты сегодня более ориентированы на личные потребности и интересы. И семья зачастую оказывается препятствием, «слабым звеном» в жизни человека. Статус полноценного члена общества все больше ассоциируется, например, с профессиональной деятельностью, с возможностью иметь свободу личного выбора во всех сферах собственной жизни. И в нашей стране стали более распространенными такие явления, как малодетность, отложенное материнство и отцовство, нестабильность брака. Также увеличивается число разводов и число одиноко проживающих людей, существует негативный образ многодетной семьи.

В то же время понятие «традиционная семья» в последние годы является одним из востребованных в российском общественно-политическом и бытовом дискурсе. Сегодня существуют различные типы семей: монородительские семьи, приемные семьи, гостевые семьи, семьи, существующие в рамках так называемого «гражданского брака», семьи с зарегистрированным браком, но проживающие раздельно. 
Современные исследователи обращают внимание на важность отца для развития личности ребенка. В традиционной семье отец выступает, как правило, в трех «лицах»: как кормилец, как высший дисциплинатор и пример для подражания, как проводник во внесемейной общественной деятельности и отношениях. В современной семье, в первую очередь городской, эти традиции ослабели по причине изменения роли женщины, вовлечения женщин в профессиональную работу, пространственной разобщенности труда и быта, тесного семейного быта, где для отца, как пишет Ю.В. Борисенко, «не предусмотрено пьедестала»[5. С. 60]. В свою очередь, женская эмансипация также позволяет ему расслабиться и покинуть пьедестал основного или единственного кормильца в семье, меняются также распределение обязанностей, когда оба супруга работают. Гендерные трансформации и кризис семьи позволяют говорить о переходном периоде в общественном восприятии отца, реализации отцовских практик. И.С.Кон определяет это как кризис отцовства [5].

В рамках традиционной модели маскулинности выделяют «традиционного отца» и «отсутствующего отца». В последнем случае речь идет о психологической, эмоциональной отстраненности отца. Это является средством сохранения социальной дистанции между детьми и отцом для поддержания отцовской власти, но в современном мире это также может быть связано с отсутствием культуры взаимодействия между отцом и детьми, недостаточным арсеналом инструментов реализации роли отца.

В рамках новой модели маскулинности выделяют типы: «ответственный отец», «вовлеченный отец», «новый отец». Общее в данных типах - это более активное включение отца в процесс ухода за ребенком и его воспитание. «Вовлеченное отцовство» предполагает также более тесную психологическую, эмоциональную связь с детьми. Отличительная черта этой новой модели отцовства заключается в том, что она в равной степени ориентирует мужчин на самореализацию в профессиональной и семейной сферах. Необходимо отметить, что здесь тоже существует определенное противоречие. С одной стороны, отцовство становится более факультативным [6], но в то же время увеличивается количество мужчин, для которых роль отца - это необходимая часть их самореализации наряду с профессиональной и социальной. Процессы унификации мужских и женских ролей в обществе и семье ставят вопрос об уникальности или же взаимозаменяемости материнских и отцовских ролей.

Переход к новой модели отцовства имеет на своем пути определенные препятствия, выраженные в существующих поло-ролевых стереотипах, тесной связи мужчины и материального обеспечения, высоких требованиях к профессиональной карьере мужчины, ограничение мужской роли в воспитании гедонистической активностью. Кроме этого, властные и контрольные функции в семье, главенство которых характерно для «традиционного отца», более престижны по сравнению с воспитанием и заботой о детях. Необходимо отметить, что мужчина как отец оценивается по традиционно женским критериям, по деятельности, которой отцы раньше никогда всерьез не занимались, к которой они социально, психологически и, возможно, биологически плохо подготовлены [7. С. 61]. В то же время в обществе мужчина традиционно оценивается, прежде всего, по своим внесемейным достижениям. Любые социальные неудачи, вроде потери работы, снижают его семейный 
статус, а вместе с ним - и самоуважение [5]. Мужчина, потерявший работу, испытывающий финансовые затруднения, проводит с детьми больше времени, но существенно страдает качество этого взаимодействия, так как факт его социальной несостоятельности, несостоятельности как «кормильца» семьи влияет существенным образом на его психологическое самочувствие и осложняет отношения с детьми. Психологическое самочувствие и психическое здоровье мужчины, отца довольно редко становится объектом изучения по сравнению, например, с изучением аналогичных вопросов материнства.

Проблема включенности отца в воспитание и повседневную жизнь своих детей касается как полных, так и неполных семей. Точной информации о количестве отцов в России, в одиночку воспитывающих детей, нет. По разным данным, число таких неполных семей составляет от 300 до 800 тысяч [8]. Термин «отец-одиночка» в российском законодательстве отсутствует. При этом одиноким отцом считается мужчина, имеющий одного ребенка или нескольких детей, мать которых умерла, пропала без вести, лишена родительских прав, долгое время пребывает в лечебном учреждении, оставила детей отцу при разводе или находится в местах лишения свободы. Дети могут быть как родные, так и не родные (отцом-одиночкой может считаться отчим, опекун, приемный отец). В большинстве случаев отец-одиночка - это мужчина около 40 лет с одним ребенком.

Одним из признаков распространения новой модели отцовства является выстраивание индивидуальных отношений с ребенком, когда отец играет множество ролей и качество взаимоотношений имеет большее значение, чем их количество. С этим связана практика отцовства, реализующаяся в ситуации развода родителей. На сегодняшний день наличие детей не является существенным препятствием для развода. В то же время вопрос воспитания детей и взаимодействия родителей после развода относится к числу наиболее значимых для супругов [9. С. 29]. По-прежнему преобладает дефицитарная модель отношений в ситуации развода и негативный образ отца, проживающего вне семьи, реализующего свою функцию факультативно и преимущество в досуговой сфере. И в этой ситуации отец нового типа, например «вовлеченный отец», зачастую становится жертвой, заложником ситуации, в которой выполнение отцовских функций и отцовская самореализация затруднены. В значительной степени на выстраивание отцовско-детских отношений в случае развода оказывает влияние мама детей.

Тем не менее, как это ни парадоксально, дети зачастую выигрывают после развода, т.к. отец выходит за рамки привычных функций «отцакормильца» и для поддержания отношений с ребенком, а нередко и для «искупления вины», например, специально продумывает и реализует стратегию и тактику отношений с ребенком, уделяя этому больше времени и смысла. Хотя, как показывают исследования [10. С. 75] в большинстве своем развод приводит к увеличению дистанции между ребенком и отцом и меняет форму и качество реализации отцовской роли в сторону сокращения ее компонентов: отец менее активно участвует в процессе формирования личности ребенка, разрываются эмоциональные и коммуникативные связи, сокращается время совместного досуга, приобретают иное качество экономическая и хозяйственно-бытовая функции. 
Кроме развода, современная семья сталкивается с множеством социальных, экономических и психологических трудностей. Например, практика подготовки женщин к материнству широко распространена, а мужчин никто не готовит к отцовству. К сожалению, и в процессе профилактической и реабилитационной социальной работы с семьей, испытывающей трудности или являющейся неблагополучной, ресурс отца используется крайне незначительно, а чаще всего игнорируется. Специалисты помогающих профессий, как правило, в своей работе с семьями опираются на женщину, мать, возлагая на нее ответственность за реабилитацию семьи, детей, мужа. Таким образом, мужчина утверждается в своей исключенности из семьи, которая подтверждается действиями представителей государственных, общественных институтов, не видящих в нем человека, способного взять на себя ответственность за семью, детей и себя. При этом ресурс отца может сыграть существенную роль в функциональном восстановлении и реабилитации семьи. Существуют примеры включения этого ресурса: создание кризисных центров для мужчин (г. Барнаул), групп взаимопомощи, центры для одиноких отцов (Екатеринбург), региональных ассоциаций отцов (Алтайский край, Челябинская область, Архангельская область и др.), специализированные интернет-ресурсы (http://papaland.ru, http://papa-pape.ru, http://www.muzhmir.ru и др.). На сегодняшний день это единичные практики, при этом отец в России обладает теми же правами и может рассчитывать на те же социальные гарантии и социальные выплаты, которые получает одинокая мать. Но фактический доступ к реализации некоторых прав у женщин и мужчин разный: определение места проживания ребенка после развода, усыновление, принятие под опеку ребенка мужчиной, «больничные» на работе в случае воспитания ребенка в неполной отцовской семье.

Современный мужчина-отец - это человек меняющийся. Происходящие трансформации носят медленный, противоречивый, сложный, порой конфликтный характер. Проблемы роли и функций мужчины в семье дают серьезный толчок к исследованиям, которые довольно долгое время было в тени изучения женского вопроса и материнства. Процесс актуализации мужской, отцовской темы в современной науке сегодня вполне закономерен и востребован обществом.

\section{Лumepamypa}

1. Кон И.С. Маскулинность в меняющемся мире // Вопросы философии. 2010. №5. С. 25-36;

2. Костерина И.В. «Ботаники» против Джеймса Бонда: некоторые тренды современной маскулинности [Электронный ресурс]: Неприкосновенный запас. 2012. №3. Режим доступа: http://magazines.russ.ru/nz/2012/3/k5.html

3. Кон И.С. Меняющиеся мужчины в изменяющемся мире // Этнографическое обозрение. 2010. № 6. C. 99-114.

4. Kay $R$. Men in Contemporary Russia: The Fallen Heroes of Post-Soviet Change? Aldershot, UK: shgate, 2006.

5. Кон И.С. Мужчина в меняющемся мире. М.: Время, 2009. 496 с.

6. Кон И.С. Кризис отцовства и вертикаль власти[Электронный доступ]:Полит.ру. 2009. Режим доступа: http://polit.ru/article/2009/12/18/fatherness/

7. Борисенко Ю.В. Психология отцовства. Москва; Обнинск: «ИГ-СОЦИН», 2007. 220 с.

8. Сивашенкова Д. Отец-одиночка: пособие по выживанию [Электронный ресурс]: Милосердие.ru - 2015. Режим доступа: https://www.miloserdie.ru/article/otets-odinochka-posobie-

po-vyzhivaniyu 
9. Воронина Т.Д. Развод как социальный феномен в современной России: причины и последствия / Опыт регионального исследования // Вестник Томского государственного университета. Философия. Социология. Политология. 2011. № 1. С. 21-31

10. Гафизова Н.Б., Смирнова Д.И. Отцовство как социальный феномен в полных и неполных семьях (вследствие развода) (на примере г. Иваново) // Женщина в российском обществе. 2015. №3\4. C. $67-77$

Podkladova Tatyana D. Tomsk State University (Tomsk, Russian Federation)

E-mail: tanyatomsk@mail.ru

DOI: $10.17223 / 1998863 X / 33 / 11$

THE MAN-FATHER IN THE FAMILY AND IN SOCIETY: INVOLVEMENT VS. EXCLUSION

Keywords: fatherhood, "involving fatherhood", parental roles, masculinity.

The article discusses fatherhood as a social phenomenon. The realization of this role is a sum of educational, domestic, economic, communicative, leisure and social control functions in the family. Fatherhood is characterized as a complex phenomenon formed as a result of interaction between normative societal regulations and individual attitudes emerging from father and child relationship and from the relationship between man and woman as parents. Father's role is slow and the "involved and caring father" is so far just the image present in the social consciousness.

\section{References}

1. Kon, I.S. (2010) Maskulinnost' v menyayushchemsya mire [Masculinity in the changing world]. Voprosy filosofii. 5. pp. 25-36.

2. Kosterina, I.V. (2012) "Botaniki" protiv Dzheymsa Bonda: nekotorye trendy sovremennoy maskulinnosti [Nerds against James Bond: Some trends of modern masculinity]. Neprikosnovennyy zapas. 3.

3. Kon, I.S. (2010) Menyayushchiesya muzhchiny v izmenyayushchemsya mire [Changing men in the changing world]. Etnograficheskoe obozrenie. 6. pp. 99-114.

4. Kay, R. (2006) Men in Contemporary Russia: The Fallen Heroes of Post-Soviet Change? Aldershot: Ashgate Publishing.

5. Kon, I.S. (2009) Muzhchina v menyayushchemsya mire [Man in the changing world]. Moscow: Vremya.

6. Kon, I.S. (2009) Krizis ottsovstva i vertikal' vlasti [The crisis of fatherness and the vertical of power]. [Online] Available from: http://polit.ru/article/2009/12/18/fatherness/.

7. Borisenko, Yu.V. (2007) Psikhologiya ottsovstva [Psychology of fatherhood]. Moscow; Obninsk: IG-SOTsIN.

8. Sivashenkova, D. (2015) Otets-odinochka: posobie po vyzhivaniyu [Single Fathers: A Survival Guide]. [Online] Available from: https://www.miloserdie.ru/article/otets-odinochka-posobie-povyzhivaniyu.

9. Voronina, T.D. (2011) Divorce as a Social Phenomenon in Contemporary Russia: Causesand Consequences. Experience in Regional Research. Vestnik Tomskogo gosudarstvennogo universiteta. Filosofiya. Sotsiologiya. Politologiya - Tomsk State University Journal of Philosophy, Sociology and Political Science. 1. pp. 21-31. (In Russian).

10. Gafizova, N.B. \& Smirnova, D.I. (2015) Ottsovstvo kak sotsial'nyy fenomen v polnykh i nepolnykh sem'yakh (vsledstvie razvoda) (na primere g. Ivanovo) [Fatherhood as a social phenomenon in complete and incomplete families (after divorce) (a case study of Ivanovo)]. Zhenshchina v rossiyskom obshchestve - Woman in Russian Society. 314. pp. 67-77. 